\title{
Maintenance of Asthma Control in Adolescents with Severe Asthma After Transitioning to a Specialist Adult Centre: A French Cohort Experience
}

\author{
Caroline Dufrois', Mélisande Bourgoin-Heck', Nathalie Lambert ${ }^{1,2}$, Jocelyne Just', \\ Aurore Bregeon ${ }^{1,2}$, Camille Taillé ${ }^{3}$, Stéphanie Wanin (1) \\ 'Department of Paediatric Allergology, Armand Trousseau University Hospital, Groupe Hospitalier Universitaire, AP-HP Sorbonne-Université, Paris, \\ France; ${ }^{2}$ Transversal Unit of Therapeutic Education of the Patient, Sorbonne University, Paris, France; ${ }^{3}$ Department of Respiratory Diseases, Hôpital \\ Bichat, Groupe Hospitalier Universitaire, AP-HP Nord-Université de Paris, Paris, France \\ Correspondence: Stéphanie Wanin, Department of Paediatric Allergology, Armand Trousseau University Hospital, Groupe Hospitalier Universitaire, \\ AP-HP Sorbonne-Université, 26, Avenue Arnold Netter, Paris, 750I2, France, Tel +33 I 878927 62, Email stephanie.wanin@aphp.fr
}

Background: The prevalence of severe asthma in adolescents is estimated at $6.7 \%$. Transition to adult health services is a vulnerable period for adolescents where there is a risk of poor treatment adherence and loss to follow-up.

Purpose: This retrospective study evaluated the maintenance of asthma control in young severe asthmatics, 6 months and 1 year after transition to a specialist adult centre.

Methods: Patients with severe asthma treated in a paediatric pulmonology centre in the Île-de-France and referred at least 6 months previously to an adult service were included. Asthma control was evaluated by measuring the ACT score and respiratory function. Patients were asked to answer an on-line questionnaire about their experiences during transition.

Results: Fifty-four adolescents with severe asthma underwent transition to the adult service between 2014 and 2021 . Thirteen patients (25\%) were lost to follow-up after an average of 22.4 months of follow-up. Three-quarters (73\%) of patients had well controlled asthma with an ACT score $\geq 20$ during transition and the majority were able to maintain good control and respiratory function ( $>60 \%$ $\mathrm{FEV}_{1}>80 \%$ ) during follow-up in adult pulmonology. Among the patients that answered the questionnaire, $64.8 \%$ were satisfied with the transition process.

Conclusion: Asthma control and respiratory function were maintained 6 months and 1 year after transition to the adult centre in the majority of patients. Most patients were satisfied with the transition process, but several improvements can be proposed, including early discussion of the medical plan and the implementation of procedures to reduce loss to follow-up.

Keywords: severe asthma, transition, adolescents, pulmonology, asthma control, adults

\section{Introduction}

Asthma is a chronic respiratory disease characterised by bronchial inflammation which affects around 400 million people worldwide. ${ }^{1}$ It is the most frequent chronic disease of children. The prevalence of asthma and its severity have continued to increase over the past few decades, particularly in adolescents and young adults. The prevalence of severe asthma during adolescence is estimated to be $6.7 \% .^{2}$

Severe asthma is defined according to European Respiratory Society /American Thoracic Society guidelines as uncontrolled asthma despite optimum treatment with high-dose inhaled corticosteroids and additional treatment taken regularly, or asthma which aggravates when treatment is reduced. ${ }^{3,4}$ Biologics represent an additional therapeutic option for the treatment of these patients. ${ }^{3}$ Severe asthma in adolescents is a risk factor for persistence of the disease into adulthood. ${ }^{5}$ Treatment and follow-up should therefore be continued until adulthood, requiring the transmission of information from paediatric pulmonology to adult pulmonology in order to assure optimal continuity of therapeutic management. It is therefore necessary to prepare young people for transition from paediatric services to the adult 
healthcare system and to establish an organised pathway to facilitate transfer in order to avoid breaks in healthcare and the loss of medical follow-up of adolescents at transition.

Adolescence is an important developmental stage in the life of an individual. During this period adolescents create their own identity and make choices about their social and professional future. The adolescent will also learn to become autonomous and to be responsible for their own health. The asthmatic adolescent should understand what is at stake in relation to the management of their disease and to assess the effect the disease could have on their life. ${ }^{6}$

Transition is a long period during which the adolescent can be prepared to include their disease in their life plan. It was defined for the first time in 1996 by the American Academy of Paediatrics as:

the intentional and planned movement of adolescents and young adults affected by physical handicaps or chronic diseases from the paediatric healthcare system to that of adults. ${ }^{7}$

Transition is a period of vulnerability where there is a risk of adolescents becoming young adults being lost to follow-up. With asthma, poor adherence to treatment is associated with an increased risk of persistent bronchial hyper-reactivity 5 years after transfer to adult healthcare. ${ }^{8}$ Although asthma is a common disease, there have been few studies on transition, particularly in adolescents and young adults with severe asthma requiring management in a specialist centre. ${ }^{4}$ A Swedish study published in 2019 reported the perception of 16 young adults with severe asthma during their transfer to an adult service. They described four main concerns: (i) the desire to have responsibilities; (ii) the need to be involved; (iii) the feeling of being excluded from the care system; and (iv) lack of engagement of adult clinicians. ${ }^{2}$ In 2020 , the European Academy of Allergy and Clinical Immunology published recommendations in order to guide healthcare professionals during the transition of adolescents with asthma or allergies. ${ }^{9}$

The main aim of this study was to evaluate the maintenance of asthma control in 54 adolescents with severe asthma at 6 months and 1 year after transition from paediatric pulmonology to a specialist adult centre. The secondary objectives were to describe the patients' experience during transition, to analyse the transition process, to determine the factors that could affect this process and to assess the clinical evolution of these patients.

\section{Materials and Methods}

\section{Study Protocol}

This retrospective, descriptive study was carried out on all young adult patients with severe asthma referred, in the context of an organised transition process, to an expert adult pulmonology centre between 1st March 2012 and 30th October 2020. Our main aim was to determine the evolution of disease control after the transition process. The transition process consisted of the transmission of medical data by the paediatric pulmonology service using a standardised form, conceived jointly by the different medical teams involved in the programme. The document consisted of a summary of the disease history, the investigations performed and treatments received, and information on schooling, family and social life. It was completed either during a meeting between the paediatric and adult pulmonologist to discuss the different aspects of management before the first consultation, or directly by the patient at the first consultation. This first consultation in the adult centre was organised by the adult pulmonologist, at a time proposed by the paediatric team, with the family having no role to play. The patients were offered a number of longer consultations preceded by a meeting with a nurse who described the function of the centre.

\section{Patients}

All adolescent patients with severe asthma referred from several paediatric pulmonology centres in the Ile-de-France to a single adult pulmonology centre were included. The transition process had to have been initiated at least 6 months previously. Patients with another chronic respiratory disease or moderate asthma were excluded.

Patients with an interval of $>12$ months between two consultations with their adult pulmonologist were considered to have a non-regular follow-up.

Patients were considered as being lost to follow-up if they had never consulted their pulmonologist after a period of $>12$ months. 


\section{Data Collection}

Medical data for each patient, from the paediatric period up to 3 years post-transition to adult pulmonology, were collected from the medical files. The main data collected were: asthma phenotype (allergic (defined as sensitisation to respiratory allergens with related allergic signs), eosinophilic (blood eosinophil count $>300 / \mathrm{mm}^{3}$ on several occasions, without any other cause), maintenance treatment, asthma control reported using the $\mathrm{ACT}^{10}$ (Asthma Control Test) score during follow-up, adherence to treatment reported by the patient during the last consultation, number of exacerbations of asthma defined by acute or subacute aggravation of respiratory symptoms and a deterioration of respiratory function compared to the usual state, ${ }^{3}$ number of hospital admissions per year for a severe exacerbation, results of respiratory function tests (forced expiratory volume/sec $\left(\mathrm{FEV}_{1}\right)(\%$ predicted for age), $\mathrm{FEV}_{1} /$ vital capacity), as well as psychosocial data, particularly professional occupation. The professions considered as high risk for asthmatic patients were those resulting in exposure to irritating substances (bakers, healthcare professionals, hair dressers, painters and decorators, joiners ....), or those carried out under certain conditions, such as physical exertion, humidity or extreme temperatures. ${ }^{11}$

\section{Control of Asthma}

In order to evaluate asthma control at the time of transition, subjects were divided into three groups according to their ACT score: (i) controlled patients (ACT $\geq 20$ ); (ii) partially controlled patients $(16 \leq \mathrm{ACT} \leq 19)$; (iii) uncontrolled patients (ACT $\leq 15$ ). Similarly, in order to evaluate respiratory function, subjects were divided into three groups: (i) $\mathrm{FEV}_{1}$ $<60 \%$ predicted; (ii) $\mathrm{FEV}_{1}$ between $60-80 \%$ predicted; (iii) patients with $\mathrm{FEV}_{1}>80 \%$ predicted (assessed by spirometry in the respiratory function test laboratory; Zapletal Standards).

\section{Questionnaire}

An on-line questionnaire evaluating the patients' experience of the transition process and their psychosocial data was made available via the site Framaforms.org. The questionnaire consisted of 48 questions, with an overall completion time of $15 \mathrm{~min}$. All responses were anonymised. Legibility of the questionnaire was evaluated using Scolarius (www.scolarius.com) software, which measures the effort required to read the questions in order to permit easy comprehension of the questions in subjects of this age. It was then tested in a real situation with an adolescent to assure good understanding of each question.

\section{Ethical Approval}

Each patient was informed in writing about the possible use of their medical data and their individual rights. They were also contacted by telephone, including those lost to follow-up, in order to obtain their consent to answer the on-line questionnaire about their experience during the transition process.

As the study did not involve any medical intervention to the patients and was of public interest, a declaration from the CNIL was registered on 13/01/2021 ( $\mathrm{N}^{\circ}$ : 20210112181149). The study was approved by the Institutional Review Board of the French Learned Society for Respiratory Medicine (Société de Pneumologie de Langue Française) (No: 2021-001).

The study complied with the Declaration of Helsinki.

\section{Statistical Analysis}

Statistical analysis was performed using Microsoft Excel version 2010 and BiostaTGV. Quantitative variables are described as mean, median or quartiles. Qualitative variables are reported as absolute number and percentages. Fisher's exact test and the Wilcoxon-Mann Whitney test were used to compare proportions as a function of the numbers found and means. An alpha risk of $5 \%$ was used and $\mathrm{p}<0.05$ was considered statistically significant.

\section{Results}

\section{Study Population}

A total of 60 patients who had transitioned to the adult pulmonology service were eligible for inclusion; six patients were excluded (disease other than asthma $(\mathrm{n}=5)$ and moderate asthma $(\mathrm{n}=1)$ ). In total, 54 patients with severe asthma underwent transition from the paediatric pulmonology service to the specialist adult centre (Figure 1). During the 


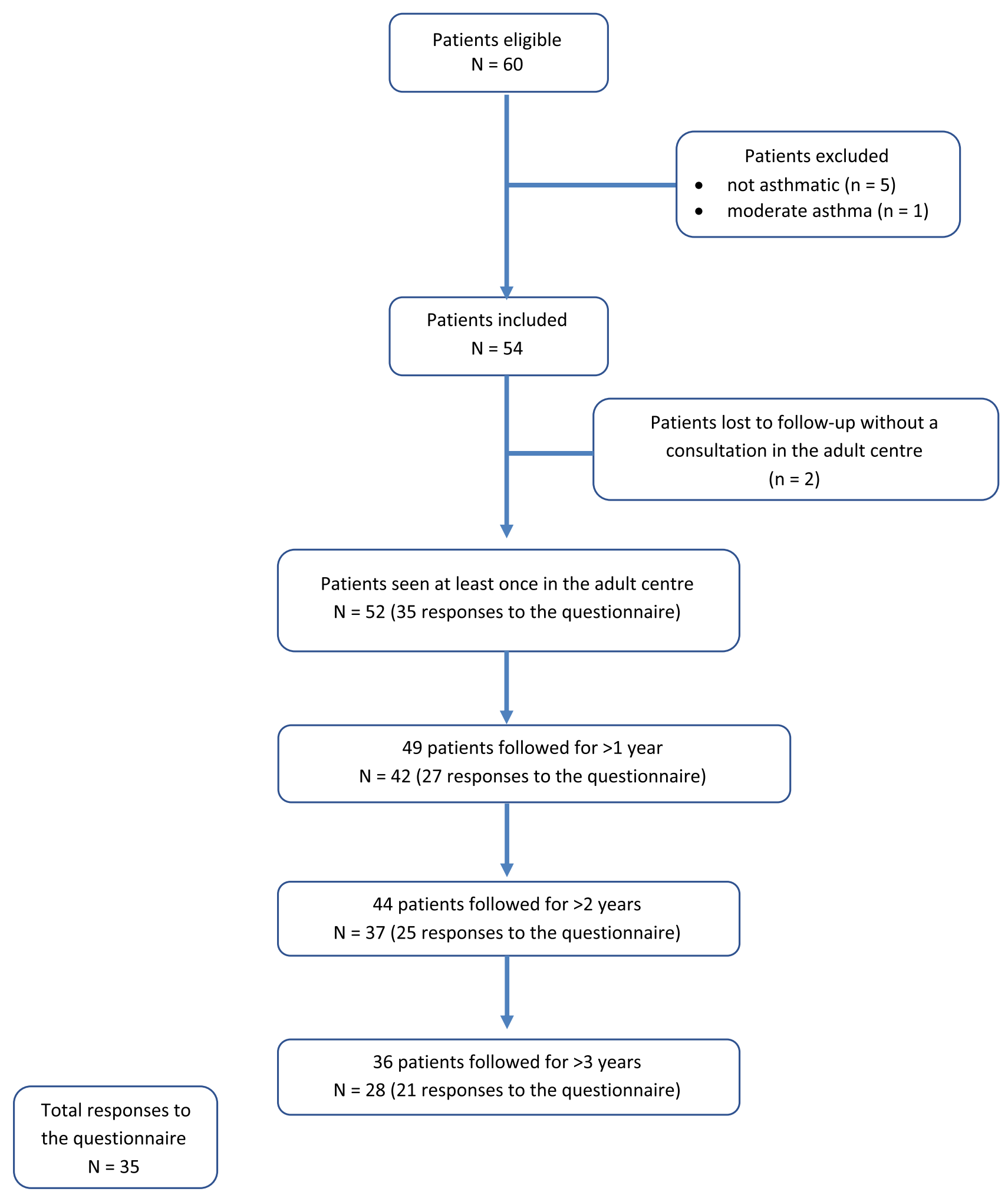

Figure I Flow chart of the study population.

study, the patients were not all in the same year after transition: three patients (5.6\%) were in their first year after transition, five patients $(9.3 \%)$ had been followed in adult pulmonology for $>1$ year and eight $(14.8 \%)$ patients for $>2$ years. The rest of the patients had participated in the transition programme for at least 3 years. Two patients never 
consulted the adult centre and were lost to follow-up. Forty-two patients were seen in consultation at 1 year after transition out of 49 patients followed, $84 \%(37 / 44)$ at 2 years and $77 \%(28 / 36)$ at 3 years.

\section{Characteristics of the Patients at the Time of Transition}

The characteristics of the patients at the time of transition are shown in Table 1 . Mean $( \pm \mathrm{SD})$ age was $18.5 \pm 1$ years. Seventy-two percent of patients (39/54) had severe allergic asthma and most of these (34/54;63\%) had associated allergic poly-morbidities (food allergy, atopic dermatitis, allergic rhino-conjunctivitis). A quarter of these patients (10/39) also had non-allergic poly-morbidities such as gastro-oesophageal reflux or obesity, and five patients $(9.3 \%)$ had non-allergic eosinophilic asthma. Thirty-five patients (64.8\%) were receiving high doses of inhaled corticosteroids (mean of $1350 \mu \mathrm{g} /$ day budesonide equivalent), associated primarily with long-acting bronchodilators. No patient was receiving long-term oral

Table I Characteristics of the Patients at the Time of Transition

\begin{tabular}{|c|c|}
\hline & Total Population $(\mathrm{N}=54)$ \\
\hline Age (years), mean \pm SD & $18.5 \pm 0.9$ \\
\hline Sex (female), n (\%) & 27 (50\%) \\
\hline BMI $\left(\mathrm{kg} / \mathrm{m}^{2}\right)$, mean $\pm \mathrm{SD}$ & $24.3 \pm 5.7$ \\
\hline Age of asthma onset (years), mean $\pm S D$ & $3.9 \pm 3.9$ \\
\hline \multicolumn{2}{|l|}{ Asthma phenotype, n (\%) } \\
\hline Allergic asthma (eosinophilic) & 39 (72.2\%) \\
\hline Asthma and allergic poly-morbidities & $34(63 \%)$ \\
\hline Non-allergic eosinophilic asthma & $5(9.3 \%)$ \\
\hline Non-allergic non-eosinophilic asthma & $10(18.5 \%)$ \\
\hline Asthma and poly-morbidities & $10(18.5 \%)$ \\
\hline \multicolumn{2}{|l|}{ Allergies, n (\%) } \\
\hline Respiratory & 40 (74\%) \\
\hline Food-related & $10(18.5 \%)$ \\
\hline Patients with $\geq 2$ allergies, $n$ (\%) & $33(61.1 \%)$ \\
\hline \multicolumn{2}{|l|}{ Asthma treatment, n (\%) } \\
\hline \multicolumn{2}{|l|}{ ICS: dose equivalent of budesonide ( $\mu \mathrm{g} /$ day) } \\
\hline Mean/median & $1350 / 1000$ \\
\hline Low dose & 7 (13\%) \\
\hline Moderate dose & II (20.4\%) \\
\hline High dose & 35 (64.8\%) \\
\hline LABA & $44(81.5 \%)$ \\
\hline LAMA & $3(5.6 \%)$ \\
\hline Nebulised anticholinergic & $7(13 \%)$ \\
\hline SABA daily & $8(14.8 \%)$ \\
\hline Montelukast & $14(26 \%)$ \\
\hline Biologics, n (\%) & $20(37 \%)$ \\
\hline Omalizumab & $18(90 \%)$ \\
\hline Mepolizumab & I (5\%) \\
\hline Benralizumab & $0(0 \%)$ \\
\hline Dupilumab & I (5\%) \\
\hline Duration of biologics (years), mean \pm SD & $3.8 \pm 2.4$ \\
\hline \multicolumn{2}{|l|}{ Adherence to treatments, $\mathrm{n}(\%)$} \\
\hline Good & $39(72.2 \%)$ \\
\hline Moderate & 14 (26\%) \\
\hline Poor & I (2\%) \\
\hline Smoker active, $\mathrm{n}(\%)$ & $3(6 \%)$ \\
\hline
\end{tabular}

Abbreviations: SD, standard deviation; BMI, body mass index; ICS, inhaled corticosteroid; LABA, long-acting beta-2 agonist (long-acting beta 2-mimetic); LAMA, long-acting muscarinic acetylcholine (long-acting anticholinergic); SABA, short-acting beta-2 agonist (short acting beta 2-mimetic). 
corticosteroids. In addition, 20 patients (37\%) received biologics for their asthma, mainly omalizumab (90\%), started at a median age of $14.5 \pm 2.2$ years. Two patients $(3.7 \%)$ who had received omalizumab during their paediatric follow-up had a change of biologic 1 year before their transition to the adult service (to dupilumab (monoclonal anti-IL4-13R antibody) and mepolizumab (monoclonal anti-IL5 antibody), respectively). In terms of the management of concomitant allergic polymorbidities, 28 patients (52\%) were receiving oral anti-histamines and four patients (7.4\%) had undergone desensitisation with specific immunotherapy. More than half of the patients had good adherence to their treatment (adherence assessed by the paediatrician) and 21 patients (38.9\%) underwent a therapeutic education programme (TEP) during their paediatric follow-up (self-care and psychosocial skills in asthma management).

\section{Parameters of Follow-Up}

Nineteen patients (36.5\%) did not have a regular follow-up (interval $>12$ months between two visits) after their transition to the adult centre, with a mean duration between two consultations of $23.5 \pm 8$ months. Among these, 13 patients (25\%) were lost to follow-up as they never had a consultation at a later date, including one patient who was lost to follow-up immediately after the first consultation in the adult centre, and 12 patients were lost to follow-up after a mean follow-up in adult pulmonology of $22.4 \pm 9$ months. Three patients $(15.8 \%)$ were receiving omalizumab at the time they were lost to follow-up and had partially controlled asthma. The main characteristics of these patients are shown in Table 2 . The majority had severe allergic asthma (80\%) and were partially controlled during follow-up.

\section{Control of Asthma}

At the time of transition from the paediatric pulmonology service to the adult service the mean ACT score was $19 \pm 6$ (median: 21 (SD: 5.7)). Thirty-one patients (73\%) had well controlled asthma (ACT score $\geq 20$ ), nine patients (15\%) were partially controlled (ACT score 16-19) and 12 patients (12\%) were not controlled (ACT score $\leq 15$ ). During the first 3 years after transition, the majority of patients had well controlled asthma: $75 \%$ at 1 year and $73 \%$ at 3 years (Figure 2). Among the patients with well controlled asthma at the time of transition, $40 \%$ maintained an ACT score of $\geq 20$ for the whole of follow-up, up to 3 years after transition. However, 3/12 patients with uncontrolled asthma at transition did not have any improvement in their asthma control and maintained an ACT score of $\leq 153$ years after transition. The characteristics of the patients with uncontrolled asthma at transition are shown in Table 3. The majority of these patients had allergic asthma with allergic poly-morbidities (75\%) and were receiving high doses of inhaled corticosteroids. There was no significant difference in the other clinical characteristics of this population when compared to the group with well controlled asthma.

There was no increase in the number of moderate and severe asthma exacerbations between the final year of followup in the paediatric service and 3 years in the adult centre (1.2 exacerbations/year). The number of emergency consultations or hospital admissions for exacerbations of asthma decreased at 3 years after transition $(19.2 \%$ vs 13.5\%). Only four patients $(7.7 \%)$ who had been hospitalised in intensive care during the last year in paediatric pulmonology had been hospitalised in intensive care again for acute severe asthma during the 3 years of follow-up in adult pulmonology.

Respiratory function was studied in 48 patients (92\%) at the time of transition (mean $\mathrm{FEV}_{1}=81 \%$ predicted (SD: 18.6)). This was stable over time with 16 patients $(31 \%)$ having a $\mathrm{FEV}_{1}>80 \%$ predicted during transition maintaining good respiratory function during follow-up until 3 years after transition (Figure 3). A small proportion of patients had a FEV 1 $<60 \%$ predicted during the 3 years after transition. The three patients with uncontrolled asthma during the whole of followup in the adult centre also maintained altered respiratory function with $\mathrm{FEV}_{1}<60 \%$ predicted.

In total, 13 patients $(25 \%)$ had well controlled asthma ( $\mathrm{ACT} \geq 20)$ with normal respiratory function $\left(\mathrm{FEV}_{1}>80 \%\right)$ at the time of transition to the adult service.

During follow-up in adult pulmonology, treatments were modified according to changes in asthma control (Table 1). A biologic (omalizumab $=3$, mepolizumab $=3$ ) was added in six patients $(11.5 \%)$ with uncontrolled asthma and one patient (2\%) had his biologic changed to an anti-IL-5 receptor monoclonal antibody (benralizumab). Conversely, due to good asthma control biologics could be stopped in $7 / 20$ patients treated at the time of transition (35\%), after a mean 
Table 2 Characteristics of the Patients Who Had a Break in Follow-Up (for at Least 12 Months) After Transition to the Adult Pulmonology Service

\begin{tabular}{|c|c|}
\hline & Population $(\mathrm{N}=19)$ \\
\hline Sex (female), n (\%) & $7(36.8 \%)$ \\
\hline \multicolumn{2}{|l|}{ Asthma phenotype, n (\%) } \\
\hline Allergic asthma (eosinophilic) & $15(80 \%)$ \\
\hline Asthma and allergic poly-morbidities & $15(80 \%)$ \\
\hline Non-allergic eosinophilic asthma & I (5.3\%) \\
\hline Non-allergic non-eosinophilic asthma & $3(15.8 \%)$ \\
\hline Asthma and poly-morbidities & $3(15.8 \%)$ \\
\hline \multicolumn{2}{|l|}{ Asthma treatment at transition, $\mathrm{n}(\%)$} \\
\hline \multicolumn{2}{|l|}{ ICS: dose equivalent of budesonide } \\
\hline Mean/median & $1511 / 1200$ \\
\hline Low dose & $3(15.8 \%)$ \\
\hline Moderate dose & $3(15.8 \%)$ \\
\hline High dose & $13(68.4 \%)$ \\
\hline Biologic, n (\%) & 7 \\
\hline Omalizumab & $7(36.8 \%)$ \\
\hline Patients who stopped biotherapy due to good asthma control, n (\%) & $4(2 \mid \%)$ \\
\hline Mean time between stopping biologics and first consultation in adult pulmonology (months), mean \pm SD & $18.3 \pm 14.4$ \\
\hline \multicolumn{2}{|l|}{ Adherence to treatment at transition, $\mathrm{n}(\%)$} \\
\hline Good & II (57.9\%) \\
\hline Moderate & $8(42.1 \%)$ \\
\hline Poor & $0(0 \%)$ \\
\hline Smoker active, $\mathrm{n}(\%)$ & $2(10.5 \%)$ \\
\hline \multicolumn{2}{|l|}{ ACT score, $\mathrm{n}$ (mean/median/SD) } \\
\hline Transition consultation with adult pulmonologist & $19(22.5 / 23 / 2.5)$ \\
\hline 6 months & $14(20.4 / 21.5 / 4.7)$ \\
\hline 12 months & $13(21.3 / 22 / 4.1)$ \\
\hline 24 months & $13(2 \mid .3 / 22 / 4.1)$ \\
\hline 36 months & $9(20 / 20 / 3.9)$ \\
\hline \multicolumn{2}{|l|}{ ACT score increasing by $\geq 3$ points, $n$ (\%) } \\
\hline 6 months & $2(14.3 \%)$ \\
\hline 12 months & $2(15.4 \%)$ \\
\hline 24 months & $3(23 \%)$ \\
\hline 36 months & I (II.I\%) \\
\hline \multicolumn{2}{|l|}{ ACT score decreasing by $\geq 3$ points, $n$ (\%) } \\
\hline 6 months & $2(14.3 \%)$ \\
\hline 12 months & I $(7.7 \%)$ \\
\hline 24 months & $4(30.8 \%)$ \\
\hline 36 months & I (II.I\%) \\
\hline
\end{tabular}

Abbreviations: SD, standard deviation; ICS, inhaled corticosteroid; ACT, asthma control test.

follow-up in the adult service of 19 months and a mean duration of biologic treatment of 5 years. This good control of asthma was maintained for at least 1 year after stopping the biologic.

\section{Process of Transition}

In total, 35 patients $(64.8 \%)$ replied to the on-line questionnaire on their experiences during the transition process. There was no significant difference between the patients who responded to the questionnaire and those who did not reply (Supplementary Table 1).

Eighty percent of patients stated that they had been pre-warned by their paediatric pulmonologist that they would continue to be monitored in the adult service at the age of $\geq 18$ years and $73.4 \%$ said that they had received information 


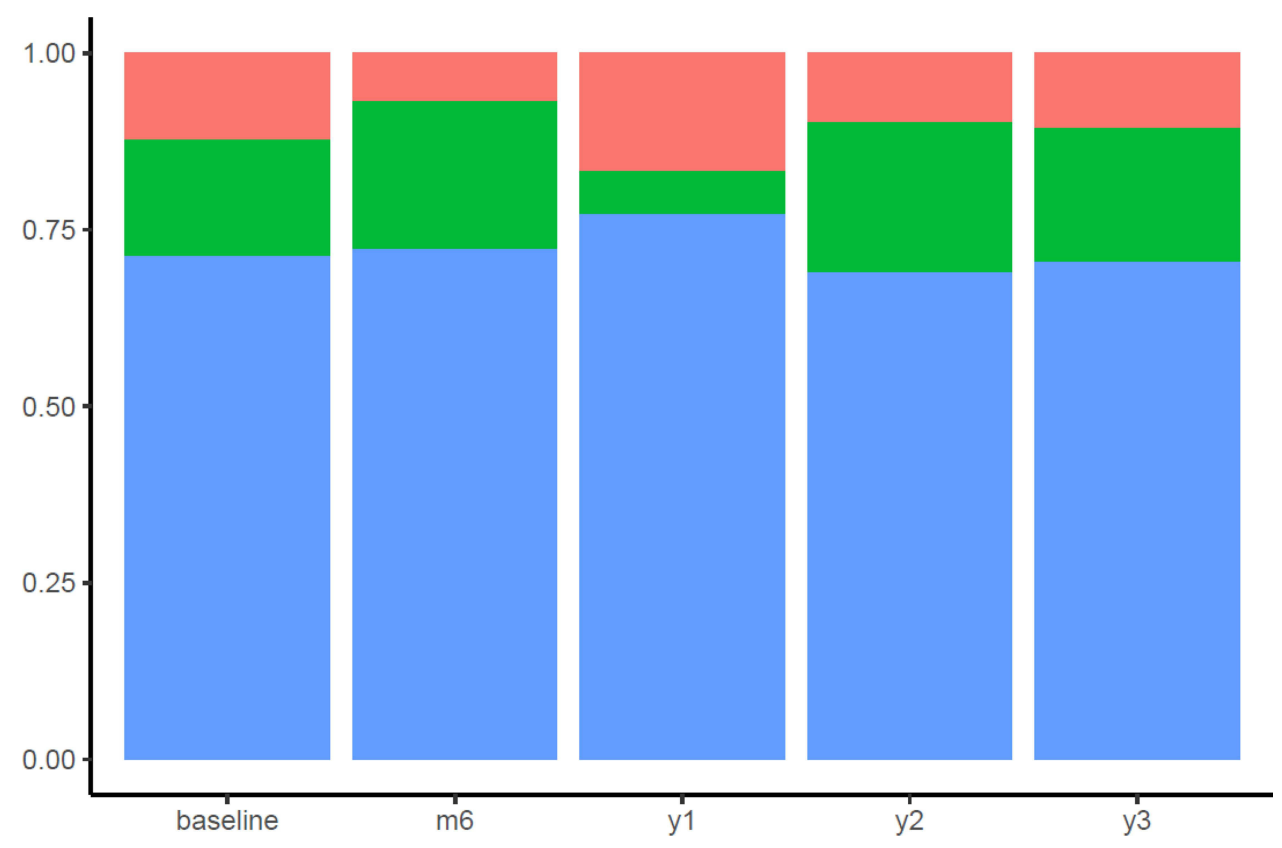

Figure 2 Distribution of ACT score among the 54 patients during transition. Well controlled asthma (ACT $\geq 20$ in blue), partially controlled asthma (ACT $16-19$ in green), uncontrolled asthma (ACT $\leq 15$ in red). $n=52$ at the first consultation in adult pulmonology, $n=43$ at 6 months after transition, $n=42$ at $I$ year, $n=37$ at 2 years, $n=28$ at 3 years.

about how this transition would take place. The patients' files were transmitted to the adult pulmonology service either after a multidisciplinary meeting between the paediatric and adult pulmonologist (26\%) or with a letter taken by the patient (70.4\%). Only two patients (3.8\%) did not undergo the transition protocol: in these two patients the meeting in the adult service was organised directly following admission to the adult pulmonology service for asthma exacerbation. No joint consultation between the paediatric and adult pulmonologist took place. In $84.6 \%$ of cases, the first meeting in the adult centre was organised at the request of the paediatric pulmonologist and took place a mean of 5 months after the last consultation with the paediatric pulmonologist. However, three patients $(5.6 \%)$ wanted to see their paediatric pulmonologist again after this first consultation before being monitored permanently in the adult centre.

During transition, more than half of the patients felt capable of managing their asthma alone on a daily basis: purchase and manage their drug supplies, remember to take their medicines and to organise medical consultations, receive help from their families when needed (88.6\%). Twenty-six patients $(74.3 \%)$ received support from one of their parents who accompanied them to their first consultation in adult pulmonology. Moreover, $22.9 \%$ and $40 \%$ of patients respectively were totally or almost ready to change their pulmonologist. Only $8.6 \%$ of patients stated that they did not feel as if they had been helped by their paediatric pulmonologist during the transition process.

From the first consultation in adult pulmonology, $85.7 \%$ of patients felt at ease and $57.1 \%$ had as much confidence in their adult pulmonologist as their paediatric pulmonologist. Half of the patients were able to ask questions during their consultation and $60 \%$ felt that their adult pulmonologist was involved in the management of their asthma.

Asthma had an impact on the professional life of one-third of patients (37.1\%) and particularly on their choice of studies; however, not all patients discussed their professional activity with their pulmonologist. Fifteen patients (27.8\%) had studies considered high risk, such as nursing, studies for a career in sports, or jobs with the possibility of exposure to chemicals fumes or dust. Among the patients who replied to the questionnaire, only three (8.6\%) said that they had discussed this with their paediatric pulmonologist, eight (22.9\%) with their adult pulmonologist and 11 (31.4\%) with both consultants. Due to their asthma, $14.3 \%$ of patients had to change studies. The other areas considered to be affected by asthma were family life $(17.1 \%)$ and friends $(20 \%)$.

The quality of life or socio-economic status of the patients were not investigated in this study and because of the small number of patients who benefited from therapeutic education, we could not study the impact of this management. 
Table 3 Comparison of Patients with Uncontrolled Asthma (ACT $\leq 15)$ and the Rest of the Population at the Time of Transition

\begin{tabular}{|c|c|c|c|}
\hline & $\begin{array}{l}\text { Uncontrolled Asthma } \\
\qquad(\mathrm{N}=12)\end{array}$ & $\begin{array}{l}\text { Rest of the Population } \\
\qquad(\mathrm{N}=40)\end{array}$ & p value \\
\hline Age (years) at transition, mean $\pm S D$ & $18.6 \pm 1.4$ & $18.4 \pm 0.77$ & 0.76 \\
\hline Sex (female), n (\%) & 7 (58.3\%) & 19 (47.5\%) & 0.78 \\
\hline BMI $\left(\mathrm{kg} / \mathrm{m}^{2}\right)$, mean \pm SD & $25.7 \pm 4.6$ & $23.8 \pm 5.9$ & 0.13 \\
\hline Age of asthma onset (years), mean $\pm S D$ & $2.9 \pm 4.3$ & $4.1 \pm 3.9$ & 0.32 \\
\hline \multicolumn{4}{|l|}{ Asthma phenotype, n (\%) } \\
\hline Allergic asthma (eosinophilic) & $9(75 \%)$ & $29(72.5 \%)$ & I \\
\hline Asthma and allergic poly-morbidities & $9(75 \%)$ & $24(60 \%)$ & 0.80 \\
\hline Non-allergic eosinophilic asthma & $2(16.7 \%)$ & $3(7.5 \%)$ & 0.59 \\
\hline Non-allergic non-eosinophilic asthma & I (8.3\%) & $8(20 \%)$ & 0.67 \\
\hline Asthma and poly-morbidities & $2(16.7 \%)$ & $8(20 \%)$ & I \\
\hline \multicolumn{4}{|l|}{ Asthma treatment at transition, $\mathrm{n}(\%)$} \\
\hline \multicolumn{4}{|l|}{ ICS: dose equivalent of budesonide } \\
\hline Mean/median & $2083 / 2000$ & $1144 / 1000$ & $0.0001 *$ \\
\hline Low dose & $0(0 \%)$ & 7 (I7.5\%) & 0.33 \\
\hline Moderate dose & $0(0 \%)$ & $10(25 \%)$ & 0.19 \\
\hline High dose & $12(100 \%)$ & $23(57.5 \%)$ & 0.23 \\
\hline LABA & $8(66.7 \%)$ & $35(87.5 \%)$ & 0.63 \\
\hline LAMA & $2(16.7 \%)$ & I (2.5\%) & 0.16 \\
\hline Nebulised anticholinergic & $4(33.3 \%)$ & $3(7.5 \%)$ & 0.08 \\
\hline SABA daily & $5(41.7 \%)$ & $3(7.5 \%)$ & $0.03^{*}$ \\
\hline Montelukast & $6(50 \%)$ & $8(20 \%)$ & 0.18 \\
\hline Biologics, n (\%) & $6(50 \%)$ & $13(32.5 \%)$ & 0.54 \\
\hline Omalizumab & $5(4 I .7 \%)$ & $12(30 \%)$ & \\
\hline Mepolizumab & I (8.3\%) & $0(0 \%)$ & \\
\hline Dupilumab & $0(0 \%)$ & I (2.5\%) & \\
\hline Duration (years) of biologic, mean $\pm S D$ & $3.2 \pm 1.5$ & $4 \pm 2.3$ & 0.56 \\
\hline \multicolumn{4}{|l|}{$\begin{array}{l}\text { Modification of biologic during follow-up in adult } \\
\text { pulmonology, } n(\%)\end{array}$} \\
\hline Biologic stopped due to improvement in asthma control & I (8.3\%) & $6(15 \%)$ & I \\
\hline Change to another biologic & I (8.3\%) & $0(0 \%)$ & 0.25 \\
\hline Addition of biologic & $4(33.3 \%)$ & $2(5 \%)$ & $0.04^{*}$ \\
\hline \multicolumn{4}{|l|}{ Adherence to treatment at transition, $\mathrm{n}(\%)$} \\
\hline Good & $12(100 \%)$ & $25(62.5 \%)$ & 0.34 \\
\hline Moderate & $0(0 \%)$ & $14(35 \%)$ & 0.06 \\
\hline Poor & $0(0 \%)$ & $\mathrm{I}(2.5 \%)$ & I \\
\hline Smoker active, n (\%) & $0(0 \%)$ & $3(7.5 \%)$ & I \\
\hline \multicolumn{4}{|l|}{ ACT score, $n$ (mean/median/SD) } \\
\hline Baseline & $10.4 / 11 / 3.4$ & $21.9 / 22 / 2.8$ & 1.69 \\
\hline 6 months & $15.3 / 16.5 / 5.4$ & $22.1 / 23 / 3.2$ & $0.0001 *$ \\
\hline 12 months & $14.9 / 13.5 / 4.8$ & $22 / 24 / 3.7$ & $0.0002 *$ \\
\hline 24 months & $15 / 17 / 4.6$ & $21.5 / 22.5 / 3.7$ & $0.003^{*}$ \\
\hline 36 months & $12.8 / 13 / 3.1$ & $21.4 / 22 / 3.6$ & $0.00 I^{*}$ \\
\hline Patients with no regular follow-up for $>12$ months, $n$ (\%) & $3(25 \%)$ & $16(40 \%)$ & 0.74 \\
\hline
\end{tabular}

Note: ${ }^{*} p<0.05$.

Abbreviations: ACT, asthma control test; SD, standard deviation; BMI, body mass index; ICS, inhaled corticosteroid; LABA, long-acting beta-2 agonist (long-acting beta 2-mimetic); LAMA, long-acting muscarinic acetylcholine (long-acting anticholinergic); SABA, short-acting beta-2 agonist (short acting beta 2-mimetic).

\section{Discussion}

Our study describes, for the first time in France, the modalities of the transition process and the experience of young adults with severe asthma during their transfer from a paediatric pulmonology service to a specialist adult centre. The 


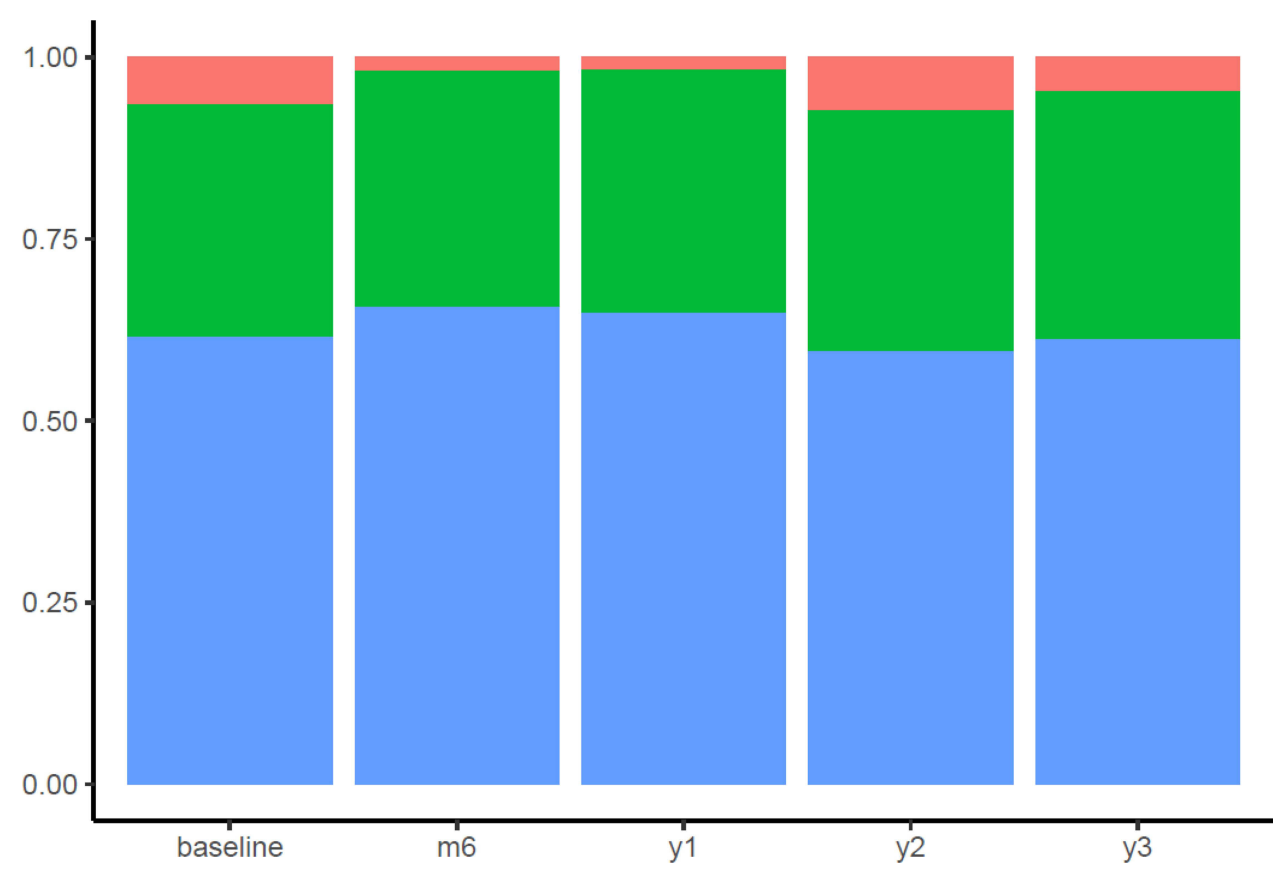

Figure 3 Distribution of $\mathrm{FEV}$, for 48 patients during transition. Patients with $\mathrm{FEV}$, $>80 \%$ (in blue), patients with $\mathrm{FEV}$, between $60-80 \%$ (in green), patients with $\mathrm{FEV}$, $<60 \%$ (in red). $n=48$ at the first consultation in adult pulmonology, $n=33$ at 6 months after transition, $n=33$ at I year, n=26 at 2 years, $n=23$ at 3 years.

majority of patients had well controlled asthma at the time of transfer and maintained good asthma control and good respiratory function at 6 months and 1 year after transition.

Our cohort is representative of the population of young adults followed for severe asthma. The allergic phenotype predominated in our patients, agreeing with different epidemiological studies reporting that severe paediatric asthma is often associated with atopy and sensitivity to pneumo-allergens. ${ }^{12-15}$

One of the main objectives of transition is to maintain good control of asthma during transfer to an adult centre. ${ }^{9}$ This objective is particularly important when the adolescents are considered to be at risk of severe exacerbations, have poor adherence to treatments and have psychological problems and addictions such as smoking. ${ }^{7}$ In addition, studies have shown that the rate of emergency consultations and hospital admissions is higher for young adults with uncontrolled asthma. An European study carried out in 2014 on 8000 adult asthmatics reported a prevalence of uncontrolled asthma of $45 \% .{ }^{16,17}$ In our study, $73 \%$ of patients had a good evolution of their asthma during their adult follow-up, with persistent control (ACT $\geq 20$ ). The continuation of follow-up in an adult centre contributed to the maintenance of well controlled disease and good respiratory function at 3 years after transition. This highlights the fact that the preparation, accompaniment and transmission of information between medical teams are important for successful transition. Few studies have investigated respiratory function during the transition of adult asthmatics, particularly patients with severe asthma. Bergström et al found similar results in a group of 53 young adults with severe asthma until 5 years after transition. Mean $\mathrm{FEV}_{1}$ at the time of transition was $95.5 \%$ and increased significantly at 5 years after transition. ${ }^{8}$ In our study, the proportion of patients with $\mathrm{FEV}_{1}>80 \%, 60-80 \%$ and $<60 \%$ remained stable.

Twelve patients (23\%) in our cohort had a mean ACT $\leq 15$ at the time of transfer to the adult centre of which three maintained this poor asthma control with altered respiratory function at 3 years after transition. In contrast, Bergström et al found an improvement in $\mathrm{FEV}_{1}(>80 \%)$ in $9 / 11$ adult asthmatics at 5 years after transition. ${ }^{8}$ This suggests that it would be interesting to continue the follow-up of our cohort beyond 3 years. The persistence of poor asthma control in this subgroup may be explained by different factors: more severe allergic asthma, asthma difficult to control, irregular medical follow-up or poor adherence to treatments, ${ }^{16}$ but may also represent a specific subgroup of patients with severe asthma. These observations were also found in patients with uncontrolled asthma in our cohort, where asthma was predominantly allergic; three patients in this subgroup had a break in follow-up for $>12$ months. However, adherence 
estimated by the paediatric pulmonologist was not bad, but this was declarative. In addition, a New Zealand study investigated the predictive factors for persistence or relapse of asthma in a cohort of 613 asthmatic children from birth to 26 years of age. The main predictive factors identified were: sensitivity to mites, bronchial hyperactivity, persistence of poor respiratory function, female sex, smoking and symptom onset at a young age. ${ }^{5}$ In our cohort, the declared rate of smoking was low at $6 \%$.

Continuation of follow-up in a specialist adult centre had the advantage of maintaining asthma control, of continuing the medical expertise and modifying treatments if necessary. This was particularly important as remission is difficult to obtain in severe asthma and the addition of biotherapy may help to achieve this. ${ }^{4,18}$ In our cohort, six patients had the addition of biotherapy and one patient changed their biotherapy to optimise their management after their transition to adult pulmonology. However, there was no clear improvement in their ACT and $\mathrm{FEV}_{1}$ at 3 years after transition, but the time interval was short as these modifications to therapy were more recent. Conversely, $35 \%$ of patients who received biotherapy during their transition were able to stop their biotherapy because of continued good control of their disease. This control persisted 1 year after stopping biotherapy. A longer follow-up with a larger number of patients is necessary in order to determine the factors associated with milder severity in adolescence, notably the impact of early treatment with omalizumab on the future of asthmatic patients. ${ }^{19}$

The transition model presented in our study resulted in the high satisfaction of young adults followed in the adult centre; $85.7 \%$ of patients felt comfortable with their adult pulmonologist from the first consultation and more than half were autonomous with regard to the management of their disease. This positive feeling by the patients was a result of different factors: involvement of the adolescent in the organisation of the transition process, identification of the adult pulmonologist before transfer, preparation prior to the first consultation in adult pulmonology via a transfer document containing medical data or a multidisciplinary meeting, support of the first meeting by the adult centre and regular follow-up consultations in order to maintain good asthma control. By contrast, the percentage (38.9\%) of patients undergoing a TEP was low. This is also described in the transition process and may support adherence to treatment, follow-up and a feeling of empowerment, which may avoid subsequent losses to follow-up. Recent European recommendations on transition insist on the importance of starting this process from the age of 11-13 years depending on the maturity of the adolescent, their autonomy and the stability of the disease, and to carry out a personalised transition plan in order to fulfil personal objectives and to evaluate progress over this period. ${ }^{9}$ In addition, Ödling et al also described the wishes of 16 young people with severe asthma to play a role in improving their transition and disease control. ${ }^{2}$ Good execution of the transition process is important because it can have consequences on the quality of life of the adolescent which is often altered, particularly in severe asthma. ${ }^{20}$

However, the transition process can still be improved. TEPs appear to be an important step in optimal transition and should be proposed to each patient. Specific TEP themes will allow the patient, at the time of transition, to take ownership of their disease and reinforce their capacity to act on their own health by developing competences of selfcare, management of their way of life, and to understand and use the healthcare and psychosocial care system. It will also permit parents, who are the main players in the success of this transition, to accompany the patient on their journey. Structures of adolescent medicine will help to develop specific questionnaires, such as Good2Go or the Transition Readiness Assessment Questionnaire, which can be used to help healthcare professionals objectively evaluate the readiness of adolescents for follow-up in an adult pulmonology service. ${ }^{21-23} \mathrm{We}$ can envisage the presence of an adolescent/young adult coordinator to accompany the family from the paediatric service to the adult pulmonologist in order to support continuity of care, the autonomy of the patient and to facilitate the partnership between the different players in transition. The parents of a child with a chronic disease play a central role in the management of the disease for the whole duration of childhood. Medical decisions are obviously taken with young adults, but it would be logical to continue to involve the parents in the care of their offspring, while ensuring a private life and confidentiality. In our study, $74.3 \%$ of patients were accompanied by one parent during the first consultation in the adult centre. It is also necessary to involve the parents in the educational journey in order to help them in their role supporting a young adult.

It is important to update the training of healthcare professionals who will care for these adolescents. An European study in 2020 including 1179 paediatric and adult pulmonologists reported that $86 \%$ of healthcare professionals did not 
have a transition protocol for their service. ${ }^{24}$ It is important that paediatric pulmonologists make up part of the network and are connected with the adult medical teams to assure the relay of information and to be able to have a prior discussion about the difficulties encountered during the paediatric period. Furthermore, despite the execution of a good transition process, a significant percentage of patients are still lost to follow-up after transfer to the adult pulmonology service. ${ }^{25}$ In particular, receiving biotherapy did not lead to good follow-up with seven patients in our cohort having a break in their follow-up of $>12$ months. Closer follow-up, with regular calls from the adult pulmonology team could improve the continuity of care.

Finally, transition takes place during a period of great upheaval for the adolescent and particularly during their choice of profession. However, several studies have shown that asthma does not interfere in the choice of career of adolescents. ${ }^{26,27}$ Bhinder et al questioned young adults aged 16-22 years about their asthma and their professional goals. Over half (55\%) of the patients indicated that their asthma had an impact on their life, but their choice of career was important for only $35 \%$ of the population, $44 \%$ did not know of any occupations likely to aggravate their disease and only $14 \%$ had discussed their choice of career with their pulmonologist. ${ }^{28}$ This illustrates the importance of making adolescents aware about the potential effects of some careers on asthma. ${ }^{11}$ In our study, only $8.6 \%$ of patients had discussed it with their paediatrician, showing the importance of worrying about it early in life, $27.3 \%$ had chosen a career considered to be risky and $14.3 \%$ had to change their occupation.

Our study has several limitations. It was a retrospective study with a small population size and a heterogeneous follow-up, which did not allow us to rigorously evaluate the proportion of patients who no longer had severe asthma as adults. Furthermore, our patients did not undergo the transition process over the same period of time. There could therefore have been a bias of memory when the on-line questionnaire was answered.

\section{Conclusion}

At the time of transition, $73 \%$ of patients had controlled asthma and the majority of patients were able to maintain control of their disease and respiratory function during follow-up. For some more severe patients who remained uncontrolled despite follow-up in a specialist adult centre, this population could correspond to a particular severity phenotype and specific modalities of follow-up could be envisaged. For others, their control fluctuated and required regular therapeutic adaptations, which were made in conjunction with follow-up in the adult expert centre. Overall, the patients were satisfied with the transition process, but improvements can by proposed, such as early discussion of the medical plan and the introduction of procedures to reduce the number of patients lost to follow-up.

\section{Abbreviations}

$\mathrm{ACT}$, asthma control test; BMI, body mass index; $\mathrm{FEV}_{1}$, forced expiratory volume in 1 second; ICS, inhaled corticosteroid; LABA, long-acting beta-2 agonist (long-acting beta 2-mimetic); LAMA, long-acting muscarinic acetylcholine (longacting anticholinergic); SABA, short-acting beta-2 agonist (short acting beta 2-mimetic); SD, standard deviation; TEP, therapeutic education programme.

\section{Acknowledgments}

The authors acknowledge the contributions of all of the study participants.

\section{Funding}

This research did not receive any specific grant from funding agencies in the public, commercial, or not-for-profit sectors.

\section{Disclosure}

Prof. Dr. Jocelyne Just reports grants and personal fees from Novartis and ALK - Abello, personal fees from sanofi, and grants from Astra zeneca, outside the submitted work; and no relationship between my conflict of interest and this submitted work. The authors report no other potential conflicts of interest for this work. 


\section{References}

1. Agache I, Akdis C, Akdis M, et al. EAACI Biologicals Guidelines-Recommendations for severe asthma. Allergy. 2020;10:all.14425.

2. Ödling M, Jonsson M, Janson C, Melén E, Bergström A, Kull I. Lost in the transition from pediatric to adult healthcare? Experiences of young adults with severe asthma. $J$ Asthma. 2020;57(10):1119-1127. doi:10.1080/02770903.2019.1640726

3. Guide de poche GINA pour le traitement et la prévention de l'asthme [GINA Pocket Guide for Asthma Treatment and Prevention]. Available from: https://ginasthma.org/wp-content/uploads/2019/09/SA-Pocket-guide-v2-French-wms.pdf. Accessed April 10, 2019. French.

4. Chung KF, Wenzel SE, Brozek JL, et al. International ERS/ATS guidelines on definition, evaluation and treatment of severe asthma. Eur Respir J. 2014;43(2):343-373. doi:10.1183/09031936.00202013

5. Sears MR. Predicting asthma outcomes. J Allergy Clin Immunol. 2015;136(4):829-836. doi:10.1016/j.jaci.2015.04.048

6. Didier A, Dutau G. Transition enfant/adulte dans la prise en charge de l'asthme: de l'enfance à l'âge adulte.Transition enfant/adulte dans la prise en charge de l'asthme: de l'enfance à l'âge adulte. [Child/adult transition in asthma management: from pediatric to adult care in adolescents with asthma: from childhood to adulthood]. Rev Francaise Allergol. 2019;59(6):409-410. doi:10.1016/j.reval.2019.08.001French.

7. Roux EL. Transition des soins pédiatriques vers les soins pour adultes chez les adolescents porteurs de maladie chronique [Transition from pediatric to adult care in adolescents with chronic disease]. Santé publique et épidémiologie. Université Pierre et Marie Curie - Paris VI; 2017. French.

8. Bergström S-E, Sundell K, Hedlin G. Adolescents with asthma: consequences of transition from paediatric to adult healthcare. Respir Med. 2010;104(2):180-187. doi:10.1016/j.rmed.2009.09.021

9. Roberts G, Vazquez-Ortiz M, Knibb R, et al. EAACI Guidelines on the effective transition of adolescents and young adults with allergy and asthma. Allergy. 2020;75(11):2734-2752. doi:10.1111/all.14459

10. Schatz M, Sorkness CA, Li JT, et al. Asthma Control Test: reliability, validity, and responsiveness in patients not previously followed by asthma specialists. J Allergy Clin Immunol. 2006;117(3):549-556. doi:10.1016/j.jaci.2006.01.011

11. Harber P, Redlich CA, Henneberger P. Work-exacerbated asthma. Am J Respir Crit Care Med. 2018;197(2):1-2.

12. Fitzpatrick A, Gaston B, Erzurum S, Teague W. Features of severe asthma in school-age children: atopy and increased exhaled nitric oxide. J Allergy Clin Immunol. 2006;118(6):1218-1225. doi:10.1016/j.jaci.2006.08.019

13. Bossley CJ, Saglani S, Kavanagh C, et al. Corticosteroid responsiveness and clinical characteristics in childhood difficult asthma. Eur Respir J. 2009;34(5):1052-1059. doi:10.1183/09031936.00186508

14. Liu AH, Babineau DC, Krouse RZ, et al. Pathways through which asthma risk factors contribute to asthma severity in inner-city children. $J$ Allergy Clin Immunol. 2016;138(4):1042-1050. doi:10.1016/j.jaci.2016.06.060

15. Pongracic JA, Krouse RZ, Babineau DC, et al. Distinguishing characteristics of difficult-to-control asthma in inner-city children and adolescents. J Allergy Clin Immunol. 2016;138(4):1030-1041. doi:10.1016/j.jaci.2016.06.059

16. Selberg S, Hedman L, Jansson S, Backman H, Stridsman C. Asthma control and acute healthcare visits among young adults with asthma-A population-based study. $J$ Adv Nurs. 2019;75(12):3525-3534. doi:10.1111/jan.14174

17. Price D, Fletcher M, van der Molen T. Asthma control and management in 8000 European patients: the REcognise Asthma and LInk to Symptoms and Experience (REALISE) survey. Prim Care Resp Med. 2014;24(1):14009. doi:10.1038/npjpcrm.2014.9

18. Upham JW, James AL. Remission of asthma: the next therapeutic frontier? Pharmacol Ther. 2011;130(1):38-45. doi:10.1016/j. pharmthera.2011.01.002

19. Ross KR, Gupta R, DeBoer MD, et al. Severe asthma during childhood and adolescence: a longitudinal study. J Allergy Clin Immunol. 2020;145 (1):140-146.e9. doi:10.1016/j.jaci.2019.09.030

20. Sundell K, Bergström S-E, Hedlin G, Ygge B-M, Tunsäter A. Quality of life in adolescents with asthma, during the transition period from child to adult: quality of life in adolescents with asthma. Clin Resp J. 2011;5(4):195-202. doi:10.1111/j.1752-699X.2010.00218.x

21. Mellerio H, Jacquin P, Trelles N, et al. Validation of the "Good2Go": the first French-language transition readiness questionnaire. Eur J Pediatr. 2020;179(1):61-71. doi:10.1007/s00431-019-03450-4

22. Wood DL, Sawicki GS, Miller MD, et al. The Transition Readiness Assessment Questionnaire (TRAQ): its factor structure, reliability, and validity. Acad Pediatr. 2014;14(4):415-422. doi:10.1016/j.acap.2014.03.008

23. Jones MR, Frey SM, Riekert K, Fagnano M, Halterman JS. Transition readiness for talking with providers in urban youth with asthma: associations with medication management. J Adolesc Health. 2019;64(2):265-271. doi:10.1016/j.jadohealth.2018.08.026

24. Khaleva E, Vazquez-Ortiz M, Comberiati P, et al. Current transition management of adolescents and young adults with allergy and asthma: a European survey. Clin Transl Allergy. 2020;10(1):40. doi:10.1186/s13601-020-00340-z

25. Ödling M, Andersson N, Hallberg J, et al. A gap between asthma guidelines and management for adolescents and young adults. $J$ Allergy Clin Immunol Pract. 2020;8(9):3056-3065.e2. doi:10.1016/j.jaip.2020.05.034

26. Moscato G, Pala G, Boillat MA, Folletti I. EAACI Position Paper: prevention of work-related respiratory allergies among pre-apprentices or apprentices and young workers: allergy prevention in apprentices. Allergy. 2011;66(9):1164-1173. doi:10.1111/j.1398-9995.2011.02615.x

27. Radon K. Do respiratory symptoms predict job choices in teenagers? Eur Respir J. 2006;27(4):774-778. doi:10.1183/09031936.06.00093005

28. Bhinder S, Cicutto L, Abdel-Qadir HM, Tarlo SM. Perception of asthma as a factor in career choice among young adults with asthma. Can Respir J. 2009;16(6):e69-75. doi:10.1155/2009/810820 


\section{Publish your work in this journal}

The Journal of Asthma and Allergy is an international, peer-reviewed open-access journal publishing original research, reports, editorials and commentaries on the following topics: Asthma; Pulmonary physiology; Asthma related clinical health; Clinical immunology and the immunological basis of disease; Pharmacological interventions and new therapies. The manuscript management system is completely online and includes a very quick and fair peer-review system, which is all easy to use. Visit http://www.dovepress.com/testimonials.php to read real quotes from published authors.

Submit your manuscript here: https://www.dovepress.com/journal-of-asthma-and-allergy-journal 